\title{
Chylous Ascites: A Review of Pathogenesis, Diagnosis and Treatment
}

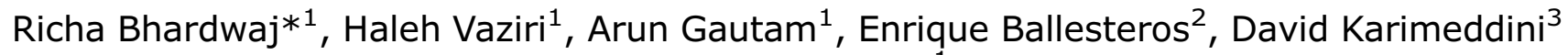 \\ and George Y. Wu ${ }^{1}$
}

\begin{abstract}
${ }^{1}$ Department of Medicine, Division of Gastroenterology-Hepatology, UCONN Health, Farmington, CT, USA; ${ }^{2}$ Department of Pathology and Lab Medicine, UCONN Health, Farmington, CT, USA; ${ }^{3}$ Department of Diagnostic Imaging and Therapeutics, UCONN Health, Farmington, CT, USA
\end{abstract}

\begin{abstract}
Chylous ascites (CA) is a rare form of ascites that results from the leakage of lipid-rich lymph into the peritoneal cavity. This usually occurs due to trauma and rupture of the lymphatics or increased peritoneal lymphatic pressure secondary to obstruction. The underlying etiologies for CA have been classified as traumatic, congenital, infectious, neoplastic, postoperative, cirrhotic or cardiogenic. Since malignancy and cirrhosis account for about two-thirds of all the cases of CA in Western countries, in this article we have attempted to reclassify CA based on portal and non-portal etiologies. The diagnosis of CA is based on the distinct characteristic of the ascitic fluid which includes a milky appearance and a triglyceride level of $>200$ $\mathrm{mg} / \mathrm{dL}$. The management consists of identifying and treating the underlying disease process, dietary modification, and diuretics. Some studies have also supported the use of agents such as orlistat, somatostatin, octreotide and etilefrine. Paracentesis and surgical interventions in the form of transjugular intrahepatic portosystemic shunt (commonly known as TIPS), peritoneal shunt, angiography with embolization of a leaking vessel, and laparotomy remain as treatment options for cases refractory to medical management.

Citation of this article: Bhardwaj R, Vaziri H, Gautam A, Ballesteros E, Karimeddini D, Wu GY. Chylous ascites: a review of pathogenesis, diagnosis and treatment. J Clin Transl Hepatol 2018;6(1):105-113. doi: 10.14218/JCTH.2017.00035.
\end{abstract}

\section{Introduction}

In 1992, the incidence of chylous ascites (CA) was reported to be approximately 1 in 20,000 admissions by a large university-based hospital over a period of 20 years. ${ }^{1}$ However, it is believed that the incidence of CA has likely increased because of increased survival rates of patients with cancer with more aggressive surgical interventions along with laparoscopic

Keywords: Chylous ascites; Portal hypertension; Cirrhosis; Ascitic fluid; Lymphatic system.

Abbreviations: ADA, adenosine deaminase; CA, chylous ascites; CA-125, cancer antigen-125; CT, computed tomography; HVPG, hepatic venous pressure gradient; MCT, medium-chain triglycerides; NMR, nuclear magnetic resonance; PHTN, portal hypertension; TIPS, transjugular intrahepatic portosystemic shunt; TPN, total parenteral nutrition; VEGF, vascular endothelial growth factor.

Received: 27 May 2017; Revised: 26 September 2017; Accepted: 30 September 2017

*Correspondence to: Richa Bhardwaj, Department of Medicine, Division of Gastroenterology-Hepatology, UCONN Health, Farmington, CT 06030, USA. Tel/Fax: +1-860-679-4613, E-mail: dr.richabhardwaj@gmail.com surgery and transplantation. ${ }^{2,3}$ Almost two-thirds of all CA cases in developed countries are associated with abdominal malignancy and cirrhosis, whereas infectious diseases, including tuberculosis, account for the majority of cases in developing countries. ${ }^{1,4,5}$ Despite the low incidence rates of CA, it is associated with mortality rates of $40-70 \%$, and an even higher morbidity rate based on the underlying etiology. ${ }^{2}$

Diagnosis is established based on clinical presentation and ascitic fluid analysis, which includes gross appearance, cell count, chemical analysis, cytology, microbiologic examination, and other special studies. Markers such as adenosine deaminase (ADA), cancer antigen-125 (CA-125) and vascular endothelial growth factor (VEGF) may have a supportive role in identifying underlying etiology. Immunohistochemical markers performed on a cell block and flow cytometry immunophenotyping can be employed to aid in establishing the diagnosis of malignancy as the etiology for CA when applicable. Newer modalities, such as nuclear magnetic resonance spectroscopy, may also have a role in establishing diagnosis. Treatment modalities are currently based on dietary measures along with the use of some pharmacological agents, such as orlistat, somatostatin, octreotide and etilefrine. Cases that are not amenable to medical management usually require surgical interventions that may include laparoscopy, laparotomy, and percutaneous embolization techniques.

This article aims to review the current literature with regards to the prevalence and etiology of $C A$, along with the current established diagnostic and treatment modalities. We have also made an attempt to classify the causes of CA based on presence or absence of underlying portal hypertension (PHTN).

Lymph formation and anatomy of lymphatic channels

Lymph is comprised of cells, particles, proteins and chylomicrons that form by the exudation of plasma and its constituents from capillaries into interstitial compartments of the body. The lymphatic system is a route by which this excess fluid from the interstitial spaces that is not reabsorbed in the postcapillary venules flows to the vascular system. Lymph passes from lymphatic capillaries into lymphatic vessels that have one-way valves, and then through lymph nodes into the lymph trunks.

The majority of lymph originates in the abdominal organs, such as the intestine and the liver. Dietary long-chain triglycerides are reduced to monoglycerides and fatty acids in the small intestine; these breakdown products are in turn 
absorbed as chylomicrons into the lymphatic system. ${ }^{6}$ This explains the high content of triglycerides in and the milky and cloudy appearance of lymph.

The lymphatic system of the abdomen is comprised of cisterna chyli and its main tributaries, the common intestinal trunk and the lumbar trunks. Cisterna chyli (or the receptaculum chyli) is a dilated sac-like receptacle in the retroperitoneum, present at the L1-2 vertebral level and which continues as the thoracic duct cranially. ${ }^{7}$ The thoracic duct enters the posterior mediastinum after passing through the aortic hiatus in the diaphragm. It continues between the aorta and azygous vein and at the level of T5 vertebrae it crosses over to the left to enter the superior mediastinum. It then empties into the venous system at the junction of the internal jugular and subclavian veins ${ }^{3}$ (Fig. 1).

\section{Pathophysiology}

Several mechanisms have been proposed for the formation of CA based on the underlying etiology, as shown in Fig. 2 .

\section{Pathophysiology in portal hypertension}

CA is commonly associated with PHTN, which is defined as elevation of the hepatic venous pressure gradient (HVPG) to $>5 \mathrm{mmHg}$. PHTN is caused by a combination of increased resistance to the passage of blood flow in the liver and increased splanchnic blood flow secondary to vasodilatation within the splanchnic vascular bed. The HVPG gives a measure of the pressure gradient between the portal vein and the inferior vena cava. It is calculated by subtracting the free hepatic venous pressure (intra-abdominal pressure) from the wedged hepatic venous pressure (portal venous pressure). These values are obtained by hepatic vein catheterization.

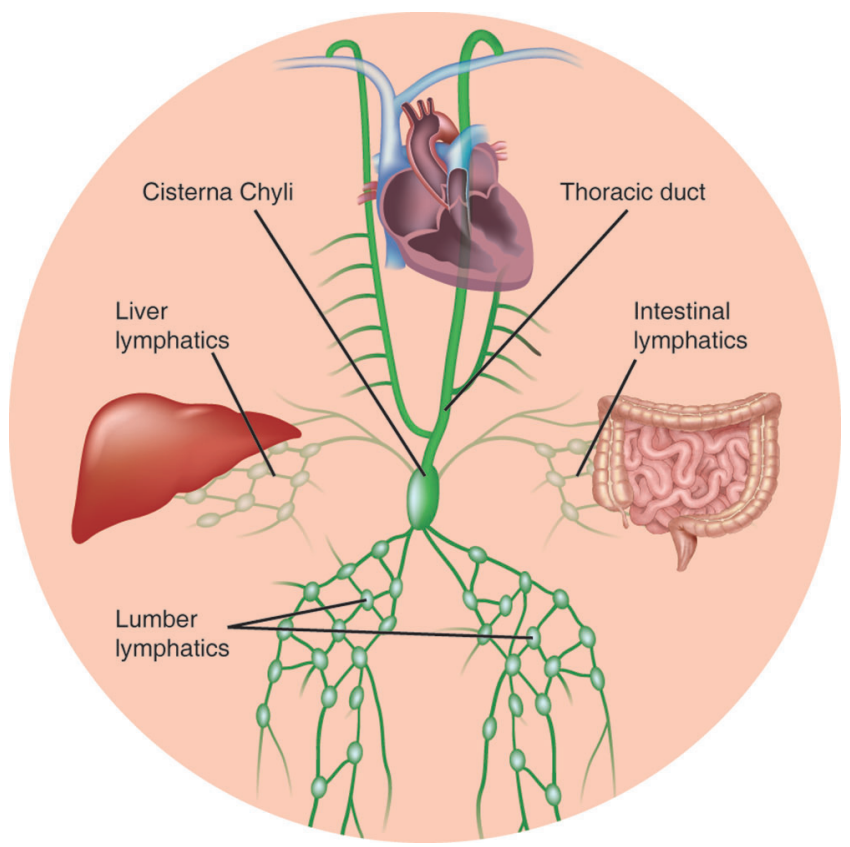

Fig. 1. A schematic representation depicting the lymphatic drainage with the major lymphatic channels in the thoraco-abdominal region.
The normal range for HVPG is $1-5 \mathrm{mmHg}$. PHTN is present if the HVPG is $\geq 6 \mathrm{mmHg}$, and a HVPG $\geq 12 \mathrm{mmHg}$ is associated with increased risk for variceal bleeding and the development of ascites. ${ }^{8,9}$ The causes of portal hypertension are usually categorized as prehepatic, intrahepatic and posthepatic. Prehepatic causes led to PHTN by affecting the portal venous system before it enters the liver, whereas posthepatic causes include those affecting the venous drainage to the heart. Intrahepatic causes constitute the majority of cases of portal hypertension, and can be further classified into presinusoidal, sinusoidal and postsinusoidal causes (Fig. 2).

The underlying pathophysiology of CA formation due to portal causes is not well understood. It has been proposed that increased caval and hepatic venous pressures cause a large increase in the production of hepatic lymph. Elevated lymphatic pressure secondary to PHTN can cause endothelial compromise or rupture of serosal dilated lymphatic channels and leads to CA formation. ${ }^{10,11}$ Cardiovascular disease, such as right-sided heart failure, constrictive pericarditis and dilated cardiomyopathy, are important causes of posthepatic PHTN, which may cause CA by increased lymph production and high resistance to lymphatic drainage due to central venous hypertension. ${ }^{12}$

\section{Pathophysiology of non-portal etiologies}

Several different mechanisms may be involved in CA formation in the setting of non-portal etiologies. These include exudation of lymph material through the walls of acquired or congenital dilated retroperitoneal vessels (megalymphatics) into the abdominal cavity through a fistula into the peritoneal cavity. These megalymphatics may also form secondary to acquired thoracic duct obstruction from trauma, resulting in direct leakage of chyle through a lymphoperitoneal fistula. Also, malignancy may cause fibrosis of the primary lymph node that may eventually obstruct the flow of lymph from the gut to the cysterna chyli, resulting in leakage from the dilated subserosal lymphatics into the peritoneal cavity. Over a period of time, this increased pressure in the lymphatic system can result in deposition of collagen in the basement membranes of the lymphatics that further impairs the absorptive capacity of the gut mucosa. ${ }^{1,3}$

\section{Etiology}

The etiologies of CA have been previously classified into traumatic or non-traumatic, congenital or acquired, malignant, inflammatory, postoperative, etc. In our review, the underlying etiologies have been classified as portal and nonportal based on the presence or absence of disease conditions affecting the underlying portal system (Figs. 2 and 3 ).

\section{Evaluation}

A detailed history and physical examination are important for making the diagnosis of CA. CA usually presents with painless and progressive abdominal distention over a course of weeks to months. Studies have reported that the most common symptom is abdominal distension ( $81 \%$ ), followed by pain or peritonitis in $11 \%$ of the cases. ${ }^{13}$ The pathogenesis of pain in CA is unclear. It has been hypothesized that the pain may result from distension of the mesenteric serosa and retroperitoneum or due to the direct contact of chyle with the peritoneal serosa. ${ }^{13}$

Patients may also complain of symptoms such as weight gain and shortness of breath, resulting from the increased 


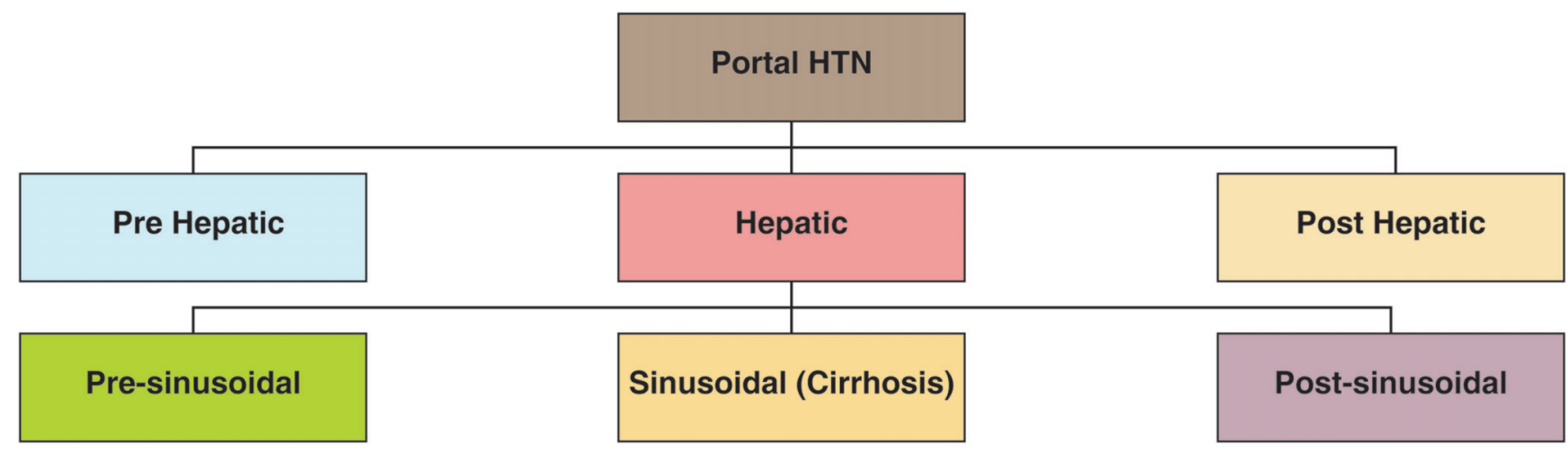

\begin{tabular}{|c|c|c|}
\hline Portal & \multicolumn{2}{|c|}{ Non-Portal } \\
\hline $\begin{array}{l}\text { Prehepatic } \\
\text { Portal vein thrombosis } \\
\text { Splenic vein thrombosis }\end{array}$ & $\begin{array}{l}\text { Congenital (mostly pediatric) } \\
\text { Primary lymphatic hypoplasia } \\
\text { Yellow nail syndrome } \\
\text { Klippel-Trenaunay syndrome } \\
\text { Primary lymphatic hyperplasia } \\
\text { Intestinal lymphangiectasia }\end{array}$ & $\begin{array}{l}\text { Neoplastic } \\
\text { Solid organ malignancy (e.g. carcinomas) } \\
\text { Lymphoma (mainly high grade } \\
\text { non-Hodgkin B-cell lymphoma) } \\
\text { Lymphangiomyomatosis } \\
\text { Carcinoid tumors } \\
\text { Kaposi sarcoma }\end{array}$ \\
\hline $\begin{array}{l}\text { Hepatic } \\
\text { Presinusoidal } \\
\text { Schistosomiasis } \\
\text { Congenital hepatic fibrosis } \\
\text { Sinusoidal } \\
\text { Cirrhosis } \\
\text { Postsinusoidal } \\
\text { Hepatic veno-occlusive disease }\end{array}$ & $\begin{array}{l}\text { Inflammatory } \\
\text { Radiation } \\
\text { Pancreatitis } \\
\text { Retroperitoneal fibrosis } \\
\text { Sarcoidosis } \\
\text { Celiac sprue } \\
\text { Whipple disease }\end{array}$ & $\begin{array}{l}\text { Postoperative } \\
\text { Abdominal aneurysm repair } \\
\text { Post-liver transplant } \\
\text { Retroperitoneal node dissection } \\
\text { Inferior vena cava resection }\end{array}$ \\
\hline $\begin{array}{l}\text { Posthepatic } \\
\text { Budd-Chiari syndrome } \\
\text { Restrictive cardiomyopathy } \\
\text { Constrictive pericarditis } \\
\text { Congestive heart failure }\end{array}$ & $\begin{array}{l}\text { Infectious } \\
\text { Tuberculosis } \\
\text { Filariasis } \\
\text { Mycobacterium avium intracellular }\end{array}$ & $\begin{array}{l}\text { Traumatic } \\
\text { Blunt abdominal trauma } \\
\text { Penetrating trauma }\end{array}$ \\
\hline
\end{tabular}

Fig. 2. Etiological classification along with differential diagnosis of various causes of portal hypertension based on the site of resistance to the portal blood flow (portal and non-portal hypertensive causes).

abdominal pressure. Non-specific symptoms, such as anorexia, malaise, diarrhea, edema, nausea, enlarged lymph nodes, early satiety, fever and night sweats, may be present. In patients with underlying cirrhosis, clinical features such as jaundice, palmar erythema, spider angiomas of the chest, and encephalopathy may be seen. History of malignancy, recent abdominal surgery, underlying liver disease, relevant family and social history (travel) should also be included in the evaluation of these patients.

\section{Paracentesis}

Abdominal paracentesis is the most important test in diagnosing CA. Chyle presents as a milky, cloudy and turbid liquid (Fig. 4). In all cases, ascitic fluid should be analyzed by gross examination, cell count, gram stain, culture, concentrations of glucose, total protein, albumin, amylase and lactate dehydrogenase, triglyceride level, and cytology. ${ }^{14}$ Acid-fast bacilli smear, culture and PCR should be performed if tuberculosis is suspected. The enzyme ADA converts adenosine to inosine and is released by macrophages and lymphocytes during the cellular immune response. ADA values in peritoneal fluid can be used as an indirect marker for tuberculous effusion. ${ }^{15}$ Some studies have reported a high sensitivity, up to $100 \%$, and a specificity of $97 \%$ using cutoff values of 36-40 IU/L. However, the test has been found to have significantly lower sensitivity in areas with low prevalence of tuberculous such as the USA. ${ }^{16}$

Identification of chylomicrons using lipoprotein electrophoresis is considered the gold standard for diagnosis of CA. However, this testing methodology is laborious and not readily available. ${ }^{17}$ Many studies have established elevated ascitic fluid triglyceride levels as the best parameter for establishing the diagnosis of CA. Several fluid triglyceride 

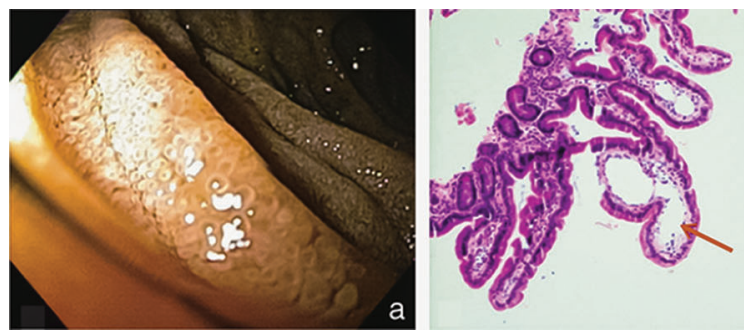

b

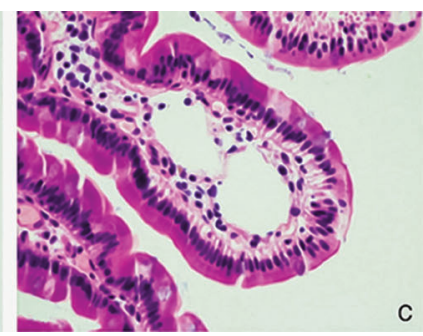

Fig. 3. Gross and histological findings. (a) Endoscopic image showing dilated duodenal villi in a patient with intestinal lymphangiectasia. (b) Tissue biopsy with hematoxylin and eosin stain, showing dilated lacteals (arrow) at 10x magnification. (c) Biopsy at 40x magnification.

cutoff values have been used for diagnosis of CA. In the past, a cutoff value of $110 \mathrm{mg} / \mathrm{dL}$ was suggested based on a study by Staat et al. ${ }^{18}$ However, the general application of this value has been questioned, as the study had utilized pleural fluid specimens to establish a diagnosis cutoff for chylous effusions. A recent study has proposed a single-point triglyceride cutoff of $187 \mathrm{mg} / \mathrm{dL}(2.13 \mathrm{mmol} / \mathrm{L})$ or alternatively an equivocal range of $148-246 \mathrm{mg} / \mathrm{dL}(1.69-2.80 \mathrm{mmol} / \mathrm{L})$ to establish CA, and observed a sensitivity and specificity up to $95 \% .{ }^{17}$ Table 1 summarizes the lab parameters that have been widely used to establish the diagnosis of CA. ${ }^{3}$ The current consensus utilizes a cutoff value of $>200 \mathrm{mg} / \mathrm{dL}$ as the criteria for diagnosis of CA. ${ }^{3,15}$

Elevated CA-125 levels may be seen in patients with ascites secondary to cirrhosis, but have been reported to be particularly elevated in patients with CA. ${ }^{11}$ Using a cutoff value of $35 \mathrm{U} / \mathrm{mL}$, the sensitivity and specificity for detection of CA in cirrhotic patients have been reported as $97.8 \%$ of $86.3 \%$, respectively. ${ }^{19}$ VEGF has also been found to play a role in the accumulation of ascitic fluid. Higher ascitic fluid VEGF concentrations are seen in cases with malignant ascites, as compared to non-malignant ascites. Newer techniques, such as nuclear magnetic resonance (1H NMR) spectroscopy of body fluids, have emerged as important tools for evaluation of ascites. The $1 \mathrm{H}$ NMR technique utilizes biochemical agents such as acetone, $\beta$-hydroxybutyrate, acetoacetate and lactate to differentiate benign ascites from malignant ascites. ${ }^{20}$ Its use in CA has, however, not been established.

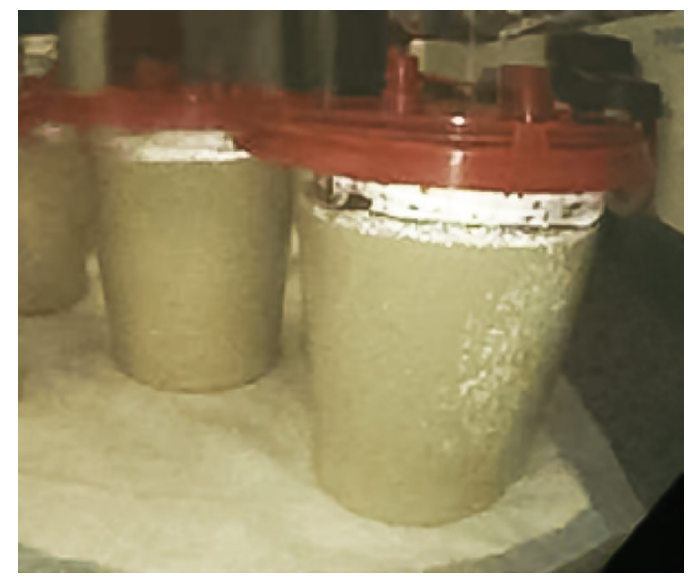

Fig. 4. Typical sample of chylous ascites, showing milky and cloudy fluid.

\section{Cytology, peritoneal biopsy and laparoscopy}

Cytology (Fig. 5) and peritoneal biopsy are important diagnostic tools in the work-up of CA. A positive fluid cytology has a high correlation with presence of peritoneal carcinomatosis, with $96.7 \%$ of patients demonstrating positive cytology. ${ }^{21}$ Sensitivity and specificity of cytology in ascitic effusions has been reported to be $62.4 \%$ and $98.0 \%$, respectively, with a positive predictive value of $100.0 \%$ and a negative predictive value of $88.3 \%$. Peritoneal fluid cytology can be improved with the use of ancillary tools, such as immunohistochemistry, to improve accuracy. ${ }^{22}$ In general, a minimum of $30 \mathrm{~mL}$ is needed for compete laboratory evaluation, including routine cell counts, chemical analysis, and microbiological examination. For cytological examination, a minimum of $100 \mathrm{~mL}$ is recommended.

The diagnosis of tuberculous peritonitis is usually established with a peritoneal biopsy. ${ }^{15}$ Peritoneal biopsy with laparoscopy has a high sensitivity and specificity for diagnosis of tuberculous and carcinomatous peritonitis. Laparoscopy can be used as a diagnostic tool, as well as a therapeutic tool. It is an accurate method for direct inspection of the peritoneal cavity and to obtain biopsy samples of suspected sites for pathology. It is especially useful in cases for which the etiology of ascites cannot be established. ${ }^{23}$

The sensitivity and specificity of laparoscopic techniques have been reported to be $84 \%$ and $100 \%$ in tuberculous peritonitis, and $100 \%$ and $92 \%$ in peritoneal carcinomatosis. ${ }^{23}$ Laparoscopy can also be used for staging of malignancies and selection of the optimal treatment for the underlying disease process. Some studies have also reported it to be the best and the most definitive method to diagnose intestinal lymphangiectasia. ${ }^{24}$

\section{Imaging}

Computed tomography (CT) of the abdomen is a useful modality to identify abdominal masses and lymph nodes that may be present in some cases of CA (Fig. 6). It may be particularly helpful in the setting of postoperative or traumatic causes of CA to determine the extent and location of possible thoracic duct injury. ${ }^{3}$ Although CT scan is the imaging modality of choice to evaluate intraperitoneal fluid accumulations, it cannot differentiate between chylous and clear ascites due to their identical densities. The pathognomonic feature of CA on CT scan is a fat fluid level. This radiological sign can be demonstrated if imaging is done after positioning the patient in a supine position for some time. The specific gravity of lipids is less than that of water which results in the formation of a fat fluid level. This sign may also be seen by ultrasonography. ${ }^{25,26}$ 
Bhardwaj R. et al: Chylous ascites

Table 1. Ascitic fluid characteristics in chylous ascites (adapted from Cardenas and Chopra, 2002)

\begin{tabular}{|c|c|}
\hline Characteristics & Value \\
\hline Color & Milky and cloudy \\
\hline Triglyceride level & $>200 \mathrm{mg} / \mathrm{dL}$ \\
\hline Cell count & $\begin{array}{l}>500 \text { (predominance of } \\
\text { lymphocytes) }\end{array}$ \\
\hline Total protein & $2.5-7.0 \mathrm{~g} / \mathrm{dL}$ \\
\hline SAAG & $\begin{array}{l}\text { Depends on the underlying } \\
\text { etiology }\end{array}$ \\
\hline Cholesterol & Low (ascites/serum ratio <1) \\
\hline $\begin{array}{l}\text { Lactate } \\
\text { dehydrogenase }\end{array}$ & Between 110-200 IU/L \\
\hline Culture & May be positive \\
\hline Amylase & Elevated in cases of pancreatitis \\
\hline Cytology & Positive in malignancy \\
\hline Glucose & $<100 \mathrm{mg} / \mathrm{dL}$ \\
\hline $\begin{array}{l}\text { Adenosine } \\
\text { deaminase }\end{array}$ & Elevated in cases of tuberculosis \\
\hline
\end{tabular}

\section{Lymphoscintigraphy and lymphangiography}

Lymphangiography and lymphoscintigraphy are modalities that can detect abnormal retroperitoneal, nodes, fistulas or leakage from lymphatic channels. They can also determine the patency of the thoracic duct. They are particularly useful in selecting patients that are suitable candidates for surgery.

Lymphoscintigraphy uses ${ }^{99} \mathrm{Tc}$ antimony sulfide colloid along with dextran or human albumin, and fluid collections can be identified by demonstration of a diffuse uptake. Additionally, it can accurately identify the sites of lymphatic leak. The ancillary use of SPECT/CT-technique can better specify

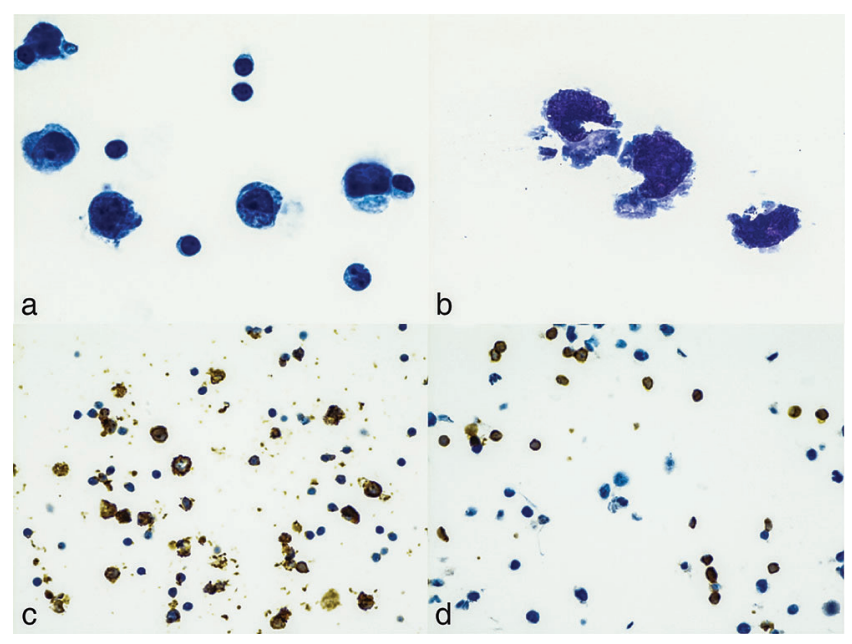

Fig. 5. Ascitic fluid cytology from a patient with chylous ascites. (a) Thin prep cytospin preparation showing a moderately cellular specimen with large cells and prominent nucleoli surrounded by benign small lymphocytes, at $60 x$ magnification. (b)Wright-Giemsa staining with three neoplastic cells and very atypical nuclei, at $100 x$ magnification. (c) Immunohistochemistry identification of CD20+ B-cells, at 40x magnification. (d) Large neoplastic cells showing negativity for the T-cell marker CD3, at 40x magnification. the anatomical sites by tomographic separation of overlapping sources, especially when planning surgical interventions. ${ }^{27}$ Lymphoscintigraphy has no significant adverse effects and hence repeat studies may be performed. However, the technical challenges associated with this technique, such as availability of specialized equipment and expertise, may make it an unfavorable diagnostic modality. ${ }^{24}$

Lymphangiography is an important technique for the detection of lymphatic leaks. Studies have reported a detection rate of $64-86 \%$ for leakage sites in patients with chylothorax and CA. ${ }^{28}$ Lymphangiography is considered the gold standard diagnostic modality in cases with lymphatic obstruction. ${ }^{3}$ Besides the diagnostic role of identifying the lymphatic leaks, some reports have also suggested a therapeutic role in cases with lymphatic leakage.

The mechanism by which lymphangiography reduces lymphatic leaks has not yet been fully elucidated, it has been suggested that lipiodol, which is an ethiodized oil contrast agent, may induce an inflammatory and granulomatous reaction on extravasation during the procedure and hence reduce leakage. Being an invasive procedure it is associated with complications such as infection, pain, and contrast extravasation during injection. Serious complications, such as intra-alveolar hemorrhage, contrast emboli in the lungs, extravasation of lipiodol into the soft tissue and allergic reactions, have also been reported. ${ }^{28}$

\section{Management}

Treatment options for CA include dietary measures, use of pharmacological agents and surgical or percutaneous interventions in some select cases (Fig. 7). The treatment modalities are targeted to provide symptomatic relief, with a focus to treat the underlying disease etiology causing CA. Malignancies account for up to $85 \%$ of cases of atraumatic CA in adults, and the presence of $\mathrm{CA}$ in malignancies usually predicts a poor prognosis. ${ }^{13,15}$ If the etiology is an underlying malignancy, modalities such as surgery, chemotherapy or radiation therapy should be instituted promptly. ${ }^{15,29}$

Surgery may be an option in certain select cases. In patients with postoperative chylothorax and $C A$, indications for surgery include chylous leak $>1000 \mathrm{~mL} / \mathrm{d}$ for $>5$ days or a persistent leak for $>2$ weeks despite optimized conservative management. Surgery may also be considered in clinical scenarios associated with development of serious nutritional or metabolic complications. ${ }^{30}$

\section{Dietary measures}

For symptomatic treatment of CA, a high-protein and low-fat diet with medium-chain triglycerides (MCT) is recommended. Dietary restriction of long-chain triglycerides avoids the requirement of conversion into monoglycerides and free fatty acids that are transported as chylomicrons by lymphatic channels. MCTs are absorbed directly from the intestine, and are transferred as free fatty acids and glycerol directly to the liver, reducing the production and flow of chyle. ${ }^{3,15}$ Coconut oil is a natural source of MCTs. However, currently there are many different synthetic MCT oils available for consumption. Unfortunately, MCTs are sometimes considered to be unpalatable and may cause abdominal distension, nausea and vomiting due to their high osmolarity, and all these factors together can result in poor dietary compliance. ${ }^{31}$ 


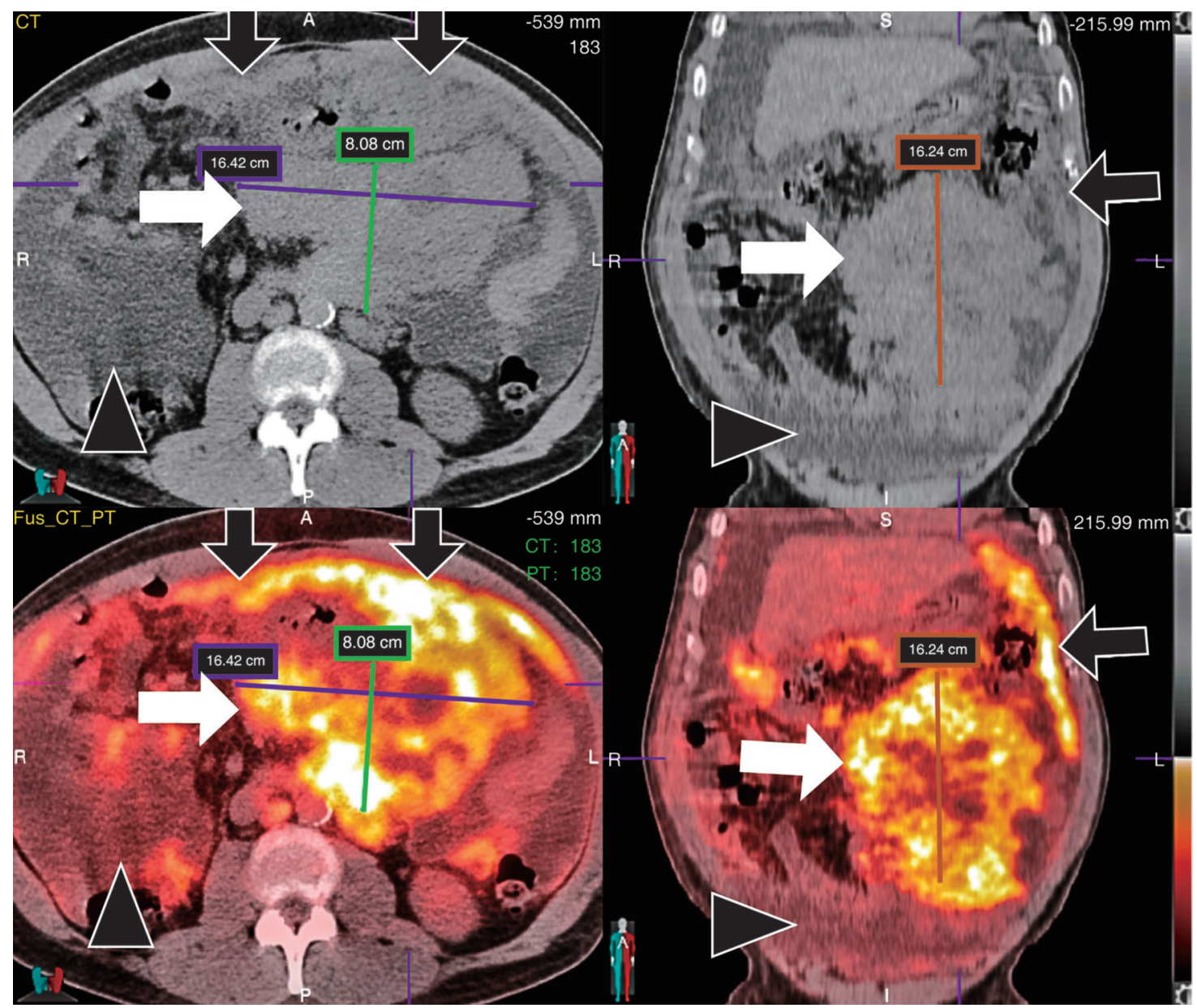

Fig. 6. Axial and coronal CT (upper panels) and fused FDG-PET/CT (lower panels) of a patient with new onset chylous ascites with fluid cytology consistent with B cell non-Hodgkin lymphoma. Images show significant FDG-avid disease in the abdomen, including a heterogeneous necrotic mesenteric mass (white arrows), omental caking (black arrows), ascites (black arrowheads) and mesenteric and retroperitoneal lymphadenopathy.

Patients with CA associated with cirrhosis should be treated with a low-sodium diet along with diuretics, such as furosemide and spironolactone. ${ }^{3}$ However, in patients with advanced cirrhosis, the benefit of MCTs is debatable. Some studies have shown that the high serum levels of MCTs in these patients may cause neurotoxicity and worsen encephalopathy, while other studies have refuted this claim. ${ }^{24,32,33}$

Patients who do not respond to the above measures should have bowel rest to reduce lymph flow and should be started on total parenteral nutrition (TPN). ${ }^{2}$ TPN bypasses the bowel and hence may reduce lymph flow. TPN formulations must be comprised of lipid formulations that are not transported through the lymphatic system and hence do not contribute to formation of chyle. ${ }^{6}$

\section{Medical therapy}

Orlistat is a reversible inhibitor of gastric and pancreatic lipase and prevents the conversion of dietary triglycerides into free fatty acids in the intestinal lumen, thereby reducing the availability of fatty acids for absorption. It has minimal systemic absorption, hence the associated side effects are primarily gastrointestinal, such as loose oily stools. ${ }^{10}$
Somatostatin reduces portal pressure by inhibiting glucagon and vasodilatation mediated by other splanchnic intestinal peptides. Somatostatin also decreases thoracic duct flow and its triglyceride content. Due to its very short half-life (1-3 $\mathrm{min}$ ) it is usually administered intravenously. Side effects may include diarrhea, hepatotoxicity, dizziness and thrombocytopenia. ${ }^{34}$ Octreotide is a synthetic version of somatostatin and has similar effects on glucagon secretion and portal pressure, but due to a longer half-life (of $\sim 2$ hours) it can be administered subcutaneously. Besides lowering the portal pressure, it also suppresses the pancreatic exocrine function and hence decreases absorption of fat from the intestine. ${ }^{35}$ Case reports have suggested that octreotide reduces the need for paracentesis, with a maximum effect in the first month and after 6 months, and it can also led to an improvement in quality of life of patients. ${ }^{11}$ It is important to note that the use of these agents is advocated in conjunction with the dietary measures mentioned above.

Etilefrine is a sympathomimetic drug used to treat postural hypotension. It has also been used successfully in the management of postesophagectomy CA with thoracic duct injury in patients with esophageal cancer. ${ }^{36}$ It has been suggested that it contracts the smooth muscles of the thoracic duct, which decreases the flow of chyle ${ }^{37}$ and hence promotes 
Bhardwaj R. et al: Chylous ascites

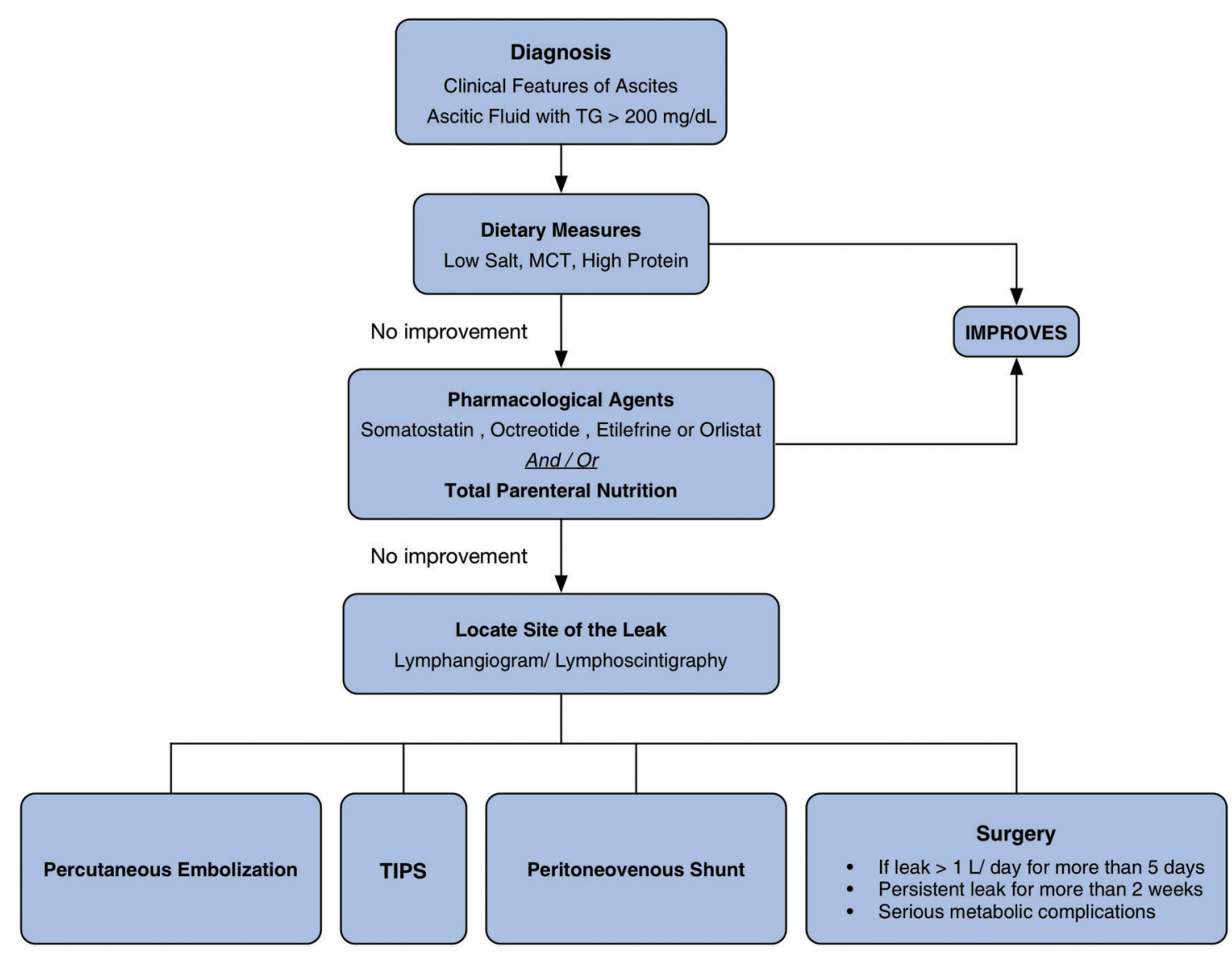

Fig. 7. Algorithm for the management of chylous ascites.

healing and closure. It is associated with side effects including headache, tachycardia and anxiety. ${ }^{36}$

\section{Percutaneous embolization}

CA can also be managed by lymphangiography along with adjunctive embolization techniques that include direct percutaneous injection of glue into the leakage site or into a nearby lymph node. A successful procedure usually leads to significant reduction in the amount of drainage, and the fluid consistency may change from milky to clear. After the procedure, the amount of drainage should be monitored to determine if the procedure was a success. Currently, there is no general consensus about the cutoff value for fluid drainage postprocedure, but most authors recommend a cutoff point of $<200-300 \mathrm{~mL} / \mathrm{d}$ as a marker of successful embolization and an indication that a drain tube can be removed. ${ }^{30,38}$ Complications may arise from migration of glue into the systemic venous system. Therefore, the glue should be closely monitored under fluoroscopy, while it is injected. The most common complaint reported postprocedure is pain in the groin or pelvis, but it is usually transient and often resolves with conservative management.

\section{Abdominal paracentesis}

In patients with symptomatic ascites, therapeutic paracentesis should be performed to relieve symptoms. Repeated large volume paracentesis may be a reasonable option for patients with end-stage liver disease who are not candidates for medical or surgical treatment. It is pertinent to note that paracentesis has both a diagnostic and a palliative role. While it does lead to prompt relief of symptoms, it is important to note that paracentesis alone is not effective and should always be combined with other conservative measures. Repeated drainage of the ascitic fluid may be associated with complications such as prolonged leak, depressed immunity, increased risk of bacterial peritonitis and increased nutritional requirements. ${ }^{26}$

\section{Transjugular intrahepatic portosystemic shunt (TIPS)}

The use of TIPS to successfully treat CA has been reported in patients with cirrhosis and CA resistant to conservative therapy. TIPS creates a communication between the portal and systemic circulations within the liver. By reducing portal pressure, it has also been shown to relieve lymphatic hypertension. ${ }^{3,39}$ When portal hypertension is the underlying pathophysiology, TIPS is more appropriate than other procedures, such as peritoneovenous shunting, as it treats the underlying cause of the CA. TIPS has a propensity to become occluded with time, with occlusion rates of up to $80 \%$ of cases within 1 year of insertion with older stents that often times required interventions such as stent angioplasty or re-stenting to restore stent patency. ${ }^{40}$ With the advent of newer stents, patency rates of up to $74 \%$ at 2 years after TIPS placement have been reported. ${ }^{41}$ Other 
complications that may be seen post TIPS are bleeding, liver failure and hepatic encephalopathy. ${ }^{42}$

\section{Peritoneovenous shunting}

Peritoneovenous shunts (LeVeen or Denver shunts) can be considered as options for patients who are refractory to medical therapy and are poor candidates for surgery. The shunt functions by returning the chylous fluid back to the blood circulation, and hence may improve the hemodynamic, nutritional and immunological statuses. ${ }^{43}$ However, these shunts are associated with a high rate of serious complications, such as hypokalemia, sepsis, small bowel obstruction, disseminated intravascular coagulation and air embolism. Additionally, the highly viscous nature of chyle can result in high rates of shunt occlusion. ${ }^{24}$ Tumor embolization has also been reported in $3 \%-7 \%$ of patients at autopsy. ${ }^{44}$

\section{Surgery}

If the above conservative management is not successful in treating CA, surgical interventions may be beneficial, especially in cases where CA is secondary to malignancy or postoperative and congenital causes. Laparotomy may be performed for fistula closure, bowel resection, or insertion of a peritoneovenous shunt. As discussed earlier, preoperative lymphangiography or lymphoscintigraphy is helpful in identifying the anatomical location of the leakage or the presence of a fistula. Once the leakage site is identified, suture ligation of the lymphatics can result in resolution of the leak. If a definitive leakage site cannot be identified, ${ }^{26}$ the retroaortic tissues may be sutured to stop the lymphatic leak. Tumor resection is a preferred modality in patients with CA secondary to neoplasia. ${ }^{45}$

\section{Prognosis}

As discussed earlier, CA is associated with mortality rates of $40-70 \%$ and an even higher morbidity rate depending on the underlying etiology. ${ }^{2}$ In general, the prognosis of non-surgical cases of CA is poorer than that of surgical cases. ${ }^{37}$ The complications associated with CA may be due to the underlying disease process itself. Also, the disease course may be further complicated by loss of fluid, protein and essential nutrients in chyle. Malignancies constitute a significant underlying etiology for CA. However, with the advent of superior chemotherapy regimens such as rituximab with combination chemotherapy, and monoclonal antibodies, there has been a marked improvement in survival rates and resolution of symptoms, especially in patients with malignancies such as lymphomas. Prior to the development of these new chemotherapy regimens, chylous effusions associated with lymphomas were associated with a dismal prognosis, with more than $90 \%$ of patients dying within 3 months of diagnosis. ${ }^{46}$

\section{Conclusions}

$\mathrm{CA}$ is a rare pathologic entity that may occur secondary to portal or non-portal etiologies. It represents a critical clinical situation which portends serious mechanical, nutritional and immunological consequences. Cirrhosis and malignancy are the most common associated underlying etiologies in adults. Diagnosis is primarily based on paracentesis, with a characteristic milky creamy gross fluid appearance and elevated fluid triglyceride levels. Treatment should be directed at the underlying pathology along with the use of conservative measures, such as dietary modification with the use of medium chain triglycerides. Pharmacological agents such octreotide, somatostatin, orlistat and etilefrine may have a role in certain scenarios. Refractory cases of CA may require interventions such as embolization, TIPS, peritoneovenous shunting or surgery. The outcome depends on the underlying etiology, and treatment strategies need to be individualized accordingly.

\section{Acknowledgments}

This work was funded in part by a grant from Alexion Corporation, and the Herman Lopata Chair in Hepatitis Research.

\section{Conflict of interest}

The authors have no conflict of interests related to this publication.

\section{Author contributions}

Collection of data, manuscript writing, drafting the article (RB), revision of manuscript, material support (HV), imaging and figures, material support, review of literature (AG), pathology inputs, material support (EB), technical and material support (DK), conception of objectives and design, revising the article for important intellectual content, critical revisions, clinical oversight and approval (GYW).

\section{References}

[1] Browse NL, Wilson NM, Russo $F$, al-Hassan $H$, Allen DR. Aetiology and treatment of chylous ascites. $\mathrm{Br}$ J Surg 1992;79:1145-1150. doi: 10.1002/bjs. 1800791110.

[2] Aalami OO, Allen DB, Organ CH Jr. Chylous ascites: a collective review. Surgery 2000;128:761-778. doi: 10.1067/msy.2000.109502.

[3] Cárdenas A, Chopra S. Chylous ascites. Am J Gastroenterol 2002;97:18961900. doi: 10.1111/j.1572-0241.2002.05911.x

[4] Khoury T, Schneider R. Chylous ascites: a rare adverse effect of methimazole treatment for grave's disease-a case report and review of the literature. Case Rep Endocrinol 2015;2015:649303. doi: 10.1155/2015/649303.

[5] Capristo E, Spuntarelli V, Treglia G, Arena V, Giordano A, Mingrone G. A case report of chylous ascites after gastric bypass for morbid obesity. Int J Surg Case Rep 2016;29:133-136. doi: 10.1016/j.ijscr.2016.10.077.

[6] Lopez-Gutierrez JC, Tovar JA. Chylothorax and chylous ascites: management and pitfalls. Semin Pediatr Surg 2014;23:298-302. doi: 10.1053/j.sempedsurg.2014.09.011.

[7] Patil AR, Nandikoor S, De Marco J, Bhat R, Shivakumar S, Mallrajapatna G. Disorders of the lymphatic system of the abdomen. Clin Radiol 2016;71: 941-952. doi: 10.1016/j.crad.2016.06.116.

[8] Groszmann RJ, Wongcharatrawee S. The hepatic venous pressure gradient: anything worth doing should be done right. Hepatology 2004;39:280-282. doi: 10.1002/hep.20062.

[9] Pinzani M, Rosselli M, Zuckermann M. Liver cirrhosis. Best Pract Res Clin Gastroenterol 2011;25:281-290. doi: 10.1016/j.bpg.2011.02.009.

[10] Chen J, Lin RK, Hassanein T. Use of orlistat (xenical) to treat chylous ascites. J Clin Gastroenterol 2005;39:831-833. doi: 10.1097/01.mcg.0000177232. 51888.2e.

[11] Berzigotti A, Magalotti D, Cocci C, Angeloni L, Pironi L, Zoli M. Octreotide in the outpatient therapy of cirrhotic chylous ascites: a case report. Dig Liver Dis 2006;38:138-142. doi: 10.1016/j.dld.2005.05.013.

[12] Güneri S, Nazli C, Kinay O, Kirimli O, Mermut C, Hazan E. Chylous ascites due to constrictive pericarditis. Int J Card Imaging 2000;16:49-54. doi: 10 . 1023/A: 1006379625554

[13] Steinemann DC, Dindo D, Clavien PA, Nocito A. Atraumatic chylous ascites: systematic review on symptoms and causes. J Am Coll Surg 2011;212:899905.e4. doi: 10.1016/j.jamcollsurg.2011.01.010. 
[14] Runyon BA. Care of patients with ascites. N Engl ] Med 1994;330:337-342. doi: 10.1056/NEJM199402033300508.

[15] Almakdisi T, Massoud S, Makdisi G. Lymphomas and chylous ascites: review of the literature. Oncologist 2005;10:632-635. doi: 10.1634/theoncologist. 10-8-632.

[16] Tarn AC, Lapworth R. Biochemical analysis of ascitic (peritoneal) fluid: what should we measure? Ann Clin Biochem 2010;47:397-407. doi: 10. 1258/acb.2010.010048.

[17] Thaler MA, Bietenbeck A, Schulz C, Luppa PB. Establishment of triglyceride cut-off values to detect chylous ascites and pleural effusions. Clin Biochem 2017;50:134-138. doi: 10.1016/j.clinbiochem.2016.10.008.

[18] Staats BA, Ellefson RD, Budahn LL, Dines DE, Prakash UB, Offord K. The lipoprotein profile of chylous and nonchylous pleural effusions. Mayo Clin Proc 1980;55:700-704.

[19] Zuckerman E, Lanir A, Sabo E, Rosenvald-Zuckerman T, Matter I, Yeshurun $D$, et al. Cancer antigen 125: a sensitive marker of ascites in patients with liver cirrhosis. Am J Gastroenterol 1999;94:1613-1618. doi: 10.1111/j. 1572-0241.1999.01152.x.

[20] Huang LL, Xia HH, Zhu SL. Ascitic fluid analysis in the differential diagnosis of ascites: focus on cirrhotic ascites. J Clin Transl Hepatol 2014;2:58-64. doi: 10.14218/JCTH.2013.00010.

[21] Runyon BA, Hoefs JC, Morgan TR. Ascitic fluid analysis in malignancy-related ascites. Hepatology 1988;8:1104-1109. doi: 10.1002/hep.1840080521.

[22] Motherby H, Nadjari B, Friegel P, Kohaus J, Ramp U, Böcking A. Diagnostic accuracy of effusion cytology. Diagn Cytopathol 1999;20:350-357. doi: 10. 1002/(SICI)1097-0339(199906)20:6<350::AID-DC5>3.0.CO;2-7.

[23] Chu CM, Lin SM, Peng SM, Wu CS, Liaw YF. The role of laparoscopy in the evaluation of ascites of unknown origin. Gastrointest Endosc 1994;40:285289. doi: 10.1016/S0016-5107(94)70057-5.

[24] Al-Busafi SA, Ghali P, Deschênes M, Wong P. Chylous ascites: evaluation and management. ISRN Hepatol 2014;2014:240473. doi: 10.1155/2014/240473.

[25] Prasad S, Patankar T. Computed tomography demonstration of a fat-fluid level in tuberculous chylous ascites. Australas Radiol 1999;43:542-543. doi: $10.1046 / j .1440-1673.1999 .00728 . x$.

[26] Shah SS, Ahmed K, Smith R, Mallina R, Akhbari P, Khan MS. Chylous ascites following radical nephrectomy: a case report. J Med Case Rep 2008;2:3. doi: 10.1186/1752-1947-2-3.

[27] Weiss M, Schwarz F, Wallmichrath J, Baumeister R, Frick A, Bartenstein P, et al. Chylothorax and chylous ascites. Clinical utility of planar scintigraphy and tomographic imaging with SPECT/CT. Nuklearmedizin 2015;54:231-240. doi: 10.3413/Nukmed-0723-15-02.

[28] Lee EW, Shin JH, Ko HK, Park J, Kim SH, Sung KB. Lymphangiography to treat postoperative lymphatic leakage: a technical review. Korean J Radiol 2014; 15:724-732. doi: 10.3348/kjr.2014.15.6.724.

[29] Press OW, Press NO, Kaufman SD. Evaluation and management of chylous ascites. Ann Intern Med 1982;96:358-364. doi: 10.7326/0003-4819-96-3358.

[30] Kawasaki R, Sugimoto K, Fujii M, Miyamoto N, Okada T, Yamaguchi M, et al. Therapeutic effectiveness of diagnostic lymphangiography for refractory postoperative chylothorax and chylous ascites: correlation with radiologic findings and preceding medical treatment. AJR Am J Roentgenol 2013; 201:659-666. doi: 10.2214/AJR.12.10008.
[31] Gracey M, Burke V, Anderson CM. Medium chain triglycerides in paediatric practice. Arch Dis Child 1970;45:445-452. doi: 10.1136/adc.45.242.445.

[32] Morgan $\mathrm{MH}$, Bolton $\mathrm{CH}$, Morris JS, Read AE. Medium chain triglycerides and hepatic encephalopathy. Gut 1974;15:180-184. doi: 10.1136/gut.15.3. 180.

[33] Uriz J, Cárdenas A, Arroyo V. Pathophysiology, diagnosis and treatment of ascites in cirrhosis. Baillieres Best Pract Res Clin Gastroenterol 2000;14: 927-943. doi: 10.1053/bega.2000.0139.

[34] Evans J, Clark MF, Mincher L, Varney VA. Chylous effusions complicating lymphoma: a serious event with octreotide as a treatment option. Hematol Oncol 2003;21:77-81. doi: 10.1002/hon.710.

[35] Talluri SK, Nuthakki H, Tadakamalla A, Talluri J, Besur S. Chylous ascites. N Am J Med Sci 2011;3:438-440. doi: 10.4297/najms.2011.3438.

[36] Guillem P, Billeret V, Houcke ML, Triboulet JP. Successful management of post-esophagectomy chylothorax/chyloperitoneum by etilefrine. Dis Esophagus 1999;12:155-156. doi: 10.1046/j.1442-2050.1999.00021.x.

[37] Alam SE, Kar SM, Kar PM. Successful management of chylous ascites: A report of two cases. Saudi J Kidney Dis Transpl 2016;27:386-390. doi: 10.4103/1319-2442.178573.

[38] Kim J, Won JH. Percutaneous treatment of chylous ascites. Tech Vasc Interv Radiol 2016;19:291-298. doi: 10.1053/j.tvir.2016.10.006.

[39] Tsauo J, Shin JH, Han K, Yoon HK, Ko GY, Ko HK, et al. Transjugular intrahepatic portosystemic shunt for the treatment of chylothorax and chylous ascites in cirrhosis: a case report and systematic review of the literature. J Vasc Interv Radiol 2016;27:112-116. doi: 10.1016/j.jvir.2015.09.022.

[40] de Vries GJ, Ryan BM, de Bièvre M, Driessen A, Stockbrugger RW, Koek GH. Cirrhosis related chylous ascites successfully treated with TIPS. Eur J Gastroenterol Hepatol 2005;17:463-466. doi: 10.1097/00042737-20050400000013.

[41] Weber CN, Nadolski GJ, White SB, Clark TW, Mondschein JI, Stavropoulos $\mathrm{SW}$, et al. Long-term patency and clinical analysis of expanded polytetrafluoroethylene-covered transjugular intrahepatic portosystemic shunt stent grafts. J Vasc Interv Radiol 2015;26:1257-1265. doi: 10. 1016/j.jvir.2015.04.005.

[42] Ripamonti R, Ferral H, Alonzo M, Patel NH. Transjugular intrahepatic portosystemic shunt-related complications and practical solutions. Semin Intervent Radiol 2006;23:165-176. doi: 10.1055/s-2006-941447.

[43] Makino Y, Shimanuki Y, Fujiwara N, Morio Y, Sato K, Yoshimoto J, et al. Peritoneovenous shunting for intractable chylous ascites complicated with lymphangioleiomyomatosis. Intern Med 2008;47:281-285. doi: 10.2169/ internalmedicine.47.0475.

[44] Sangisetty SL, Miner TJ. Malignant ascites: A review of prognostic factors, pathophysiology and therapeutic measures. World J Gastrointest Surg 2012; 4:87-95. doi: 10.4240/wjgs.v4.i4.87.

[45] Foschi D, Rizzi A, Corsi F, Trabucchi E, Corbellino M. Chylous ascites secondary to B-cell non Hodgkin's lymphoma in a patient with the acquired immune deficiency syndrome (AIDS). Dig Liver Dis 2008;40:481-482. doi: $10.1016 / j$.dld.2007.05.019.

[46] Jagosky M, Taylor B, Taylor SP. A case of chyloperitoneum secondary to follicular lymphoma and a review of prognostic implications. Case Rep Hematol 2016;2016:4625819. doi: 10.1155/2016/4625819. 